\title{
Asthma knowledge and behaviours among mothers of asthmatic children in Aseer, south-west Saudi Arabia
}

A.M. Al-Binali, ${ }^{1}$ A.A. Mahfouz, ${ }^{2}$ S. Al-Fifi, ${ }^{1}$ S.M. Naser ${ }^{3}$ and K.S. Al-Gelban ${ }^{2}$

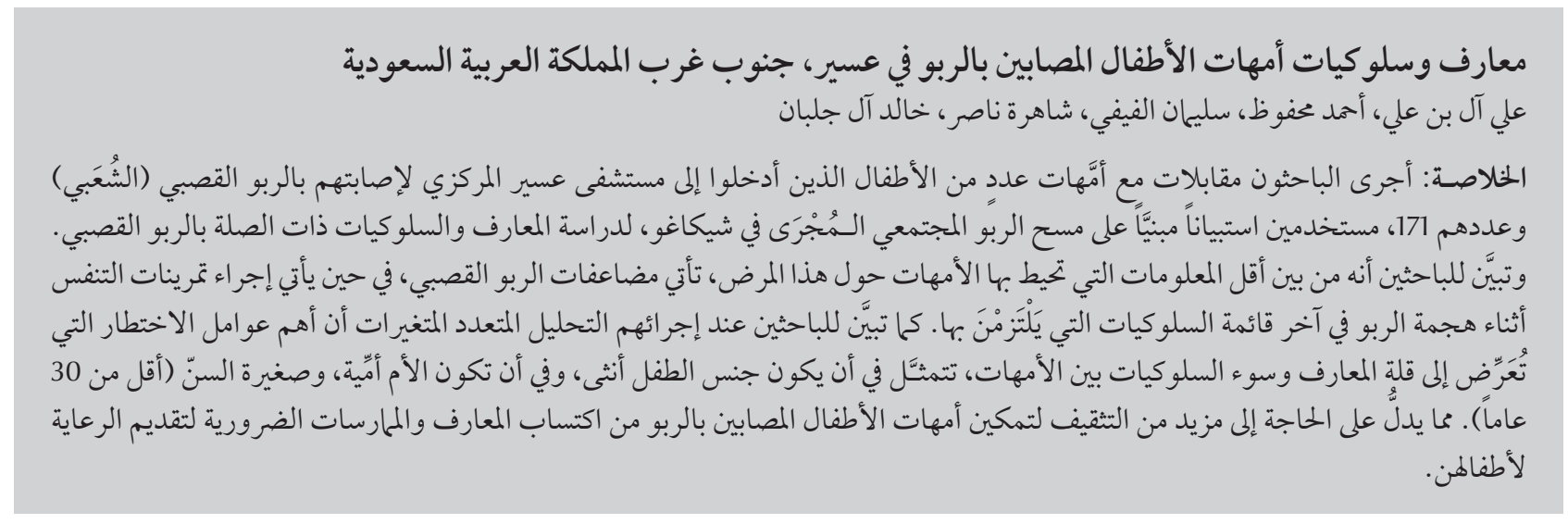

ABSTRACT Mothers of children with bronchial asthma consecutively admitted to Aseer central hospital, Saudi Arabia $(n=171)$, were interviewed using a questionnaire based on the Chicago Community Asthma Survey to study their knowledge and behaviours concerning bronchial asthma. The least known information among mothers was the complications of bronchial asthma. Breathing exercises during asthma attacks were the least practised behaviour. In a multivariate analysis, significant risk factors for poor knowledge and behaviours among mothers were female sex of the child, illiterate mother and young age of mother ( $<30$ years). More education is needed to help the mothers of asthmatic children to acquire the necessary knowledge and practices to care for their children.

Connaissances et comportements relatifs à l'asthme chez les mères d'enfants asthmatiques à Aseer, sudouest de l'Arabie saoudite

RÉSUMÉ Les mères d'enfants souffrant d'asthme bronchique admis consécutivement à I'hôpital central d'Aseer, Arabie saoudite $(n=171)$ ont été interrogées à l'aide d'un questionnaire basé sur la Chicago Community Asthma Survey afin d'étudier leurs connaissances et comportements relatifs à l'asthme bronchique. Les lacunes les plus importantes chez les mères concernaient les complications de l'asthme bronchique. Les exercices de respiration pendant les crises d'asthme étaient le comportement le moins pratiqué. Dans une analyse multivariée, des facteurs de risque importants pour les connaissances et comportements inadaptés chez les mères étaient liés aux enfants de sexe féminin, à l'illettrisme des mères et au jeune âge des mères $(<30$ ans). Il est nécessaire de renforcer l'éducation pour aider les mères d'enfants asthmatiques à acquérir les connaissances et les pratiques indispensables pour prendre soin de leurs enfants.

'Department of Child Health; ${ }^{2}$ Department of Family and Community Medicine, College of Medicine, King Khalid University, Abha, Saudi Arabia (Correspondence to A.A.Mahfouz: mahfouz@kku.edu.com.sa).

${ }^{3}$ Aseer Central Hospital, Abha, Saudi Arabia.

Received: 13/07/08; accepted: 13/10/08 


\section{Introduction}

With increasing urbanization of the world's population, it is predicted the number of individuals with asthma will increase markedly worldwide [1]. In Saudi Arabia, the reported prevalence of asthma ranges from 7\% in Dammam [2] to $12 \%$ in Riyadh [3]. Among urban schoolboys of Abha, a prevalence of $9 \%$ was found [4]. A recent communitybased study in Aseer region revealed a prevalence of bronchial asthma of $6.9 \%$ in a high altitude area and $19.5 \%$ at sea level [5].

Proper management of bronchial asthma of children requires attention to the behaviour of mothers of asthmatic children and also to the underlying beliefs which drive that behaviour.

The aim of the present work was to study the knowledge and behaviour of the mothers of children with bronchial asthma in Aseer region.

\section{Methods}

\section{Sample}

With an anticipated population proportion of $10 \%$, and an absolute precision of $5 \%$ at $95 \%$ confidence interval, the minimal sample size required for the study was calculated to be 139 mothers [6].

\section{Study instrument}

The study instrument was the Arabic version of the Chicago Community Asthma Survey [7], which had previously been tested and validated in a community-based study in Egypt [8].

As some items in the questionnaire were not clear in the Saudi Arabian context, the Egyptian colloquial Arabic version was translated into the local colloquial Arabic of Saudi Arabia. After translation and back translation, a panel of experts was asked to assess the preliminary questions and provide structured comments with respect to face and content validity, comprehensibility and comprehensiveness.

The final version of the questionnaire was distributed among a pilot test group of mothers and analysed for internal consistency. Cronbach alpha was 0.72 for knowledge scale and 0.78 for behaviours. Necessary modifications were made to the questions.

The questionnaire collects data in 2 domains - knowledge (28 items) and behaviours (18 items) - from the mothers of asthmatic children. Knowledge questions consist of dichotomous items (true/false or yes/no), which measure information related to symptoms, mechanisms, aggravating factors and complications of bronchial asthma. Behaviour questions consist of dichotomous items (true/false or yes/no) and measure mothers' behaviours during attack of asthma and behaviours to prevent the attacks.

Background data were also collected about the sex and age of the child, duration of bronchial asthma, parental level of education (illiterate or educated) and mother's working status (working or not)

\section{Data collection}

The target population was all mothers of children who were consecutively admitted with bronchial asthma to the department of paediatrics of Aseer Central Hospital over a 1-year period (1 July 2006 to 30 June 2007).

During their child's stay in the hospital, the mothers were invited to participate in the study and their informed consent was obtained. The response rate was $90.0 \%$. Trained, Arabic-speaking nurses interviewed the mothers who agreed to participate and completed the questionnaire. On average, each interview lasted for 10 -15 minutes.

\section{Analysis}

Data were analysed using SPSS PC.

Mother's knowledge and behaviours items were given scores ( 0 for poor knowledge or behaviour and 1 for good knowledge or behaviour). For each mother a total score on the 28 knowledge items and 18 behaviour items was calculated. A total score less than or equal to the 50th percentile of the total score was regarded as "poor" knowledge.

Binary logistic regression analysis was performed to identify potential risk factors for poor knowledge and behaviours concerning asthma.

\section{Results}

\section{Description of the study sample}

During the study period 171 mothers of asthmatic children were interviewed and enrolled in the study. The mothers' ages ranged from 22 to 45 years with a mean of 33.9 [standard deviation (SD) 7.8 years. Illiterate mothers were $17.5 \%$ and the rest were educated. Only $28.7 \%$ were working.

The ages of their asthmatic children ranged from 3-11 years with a mean of 6.3 (SD 2.3) years. They included 58 males $(33.9 \%)$ and 113 females (66.1\%). The duration of suffering bronchial asthma ranged from 1 to 8 years.

\section{Knowledge about bronchial asthma among mothers of asthmatic children}

The least known symptoms of bronchial asthma were shortness of breath (48.5\%) and feeling of tightness in the chest (57.9\%) (Table 1). A high proportion of mothers (84.4\%) did not know the mechanism by which bronchial asthma occurs. A majority of mothers recognized the common cold, weather changes and insecticides as aggravating factors of bron- 
chial asthma $(94.7 \%, 82.5 \%$ and $61.4 \%$ respectively).

The least known information among mothers were the complications of bronchial asthma; sleep disorders, respiratory failure and death were identified as complications of asthma by only $10.5 \%, 9.9 \%$ and $9.9 \%$ of mothers respectively. Regarding the symptoms of severe attacks of bronchial asthma, the majority of mothers identified severe shortness of breath, persistent severe cough and inability to talk or walk as symptoms of severe attacks ( $80.1 \%$, $79.5 \%$ and $74.9 \%$ respectively).

\section{Behaviours of mothers concerning their children's bronchial asthma}

Regarding behaviours during asthma attacks all mothers (100\%) agreed that they gave necessary medications and a majority massaged the child's chest (89.5\%), let the child cough to clear mucus from the lungs ( $82.5 \%)$ and minimized the child's movements (73.1\%) (Table 2). Nearly one-third of mothers (29.2\%) said they would ask for help.

As for mothers' behaviours to prevent asthma attacks, all mothers (100\%) gave the necessary medications regularly and the majority cleaned the house to remove dust (94.2\%), removed aggravating factors from the house (92.4\%) and treated attacks of common cold (77.2\%). Breathing exercises (physiotherapist-taught) were the least practised behaviour during the bronchial asthma attack (9.4\%) or to prevent $\operatorname{attacks}(14.1 \%)$.

\section{Determinants of mothers' poor knowledge and behaviours regarding bronchial asthma}

There were 103 mothers (60.2\%) with poor knowledge scores and $65(38.0 \%)$ with poor behaviour scores.

After adjusting each potential risk factor in a multivariate analysis model, the mothers of female children

Table 1 Knowledge about bronchial asthma among mothers of asthmatic children in Aseer, south-west Saudi Arabia

Knowledge item No. of mothers $\%(n=171)$

Symptoms of bronchial asthma

$\begin{array}{lrr}\text { Wheeze } & 171 & 100.0 \\ \text { Cough } & 145 & 84.8 \\ \text { Feeling of tightness in chest } & 99 & 57.9 \\ \text { Shortness of breath } & 83 & 48.5\end{array}$

\section{Mechanisms of bronchial asthma}

Don't know $\quad 145 \quad 84.4$

$\begin{array}{lll}\text { Inflammation leading to obstruct bronchi } & 18 & 10.5\end{array}$

$\begin{array}{lll}\text { Mucus obstructing bronchi } & 18 & 10.5\end{array}$

$\begin{array}{lll}\text { Narrowing in bronchi } & 16 & 9.4\end{array}$

Aggravating factors of bronchial asthma

$\begin{array}{lrr}\text { Common cold } & 162 & 94.7 \\ \text { Weather changes } & 141 & 82.5 \\ \text { Insecticides } & 105 & 61.4 \\ \text { Exhaustion } & 79 & 46.2 \\ \text { Dust } & 74 & 43.3 \\ \text { Smoke } & 50 & 29.2 \\ \text { Food } & 33 & 19.3 \\ \text { Muscular exercise } & 19 & 11.1 \\ \text { Psychological } & 8 & 4.7\end{array}$

\section{Complications of asthma}

$\begin{array}{lll}\text { Chest cage deformities } & 26 & 15.2\end{array}$

$\begin{array}{lll}\text { Sleep disorders } & 18 & 10.5\end{array}$

$\begin{array}{lll}\text { Respiratory failure } & 17 & 9.9\end{array}$

$\begin{array}{lll}\text { Sudden death } & 17 & 9.9\end{array}$

Affects child's development $\quad 3 \quad 1.8$

Symptoms of severe attack of asthma

$\begin{array}{lll}\text { Severe shortness of breath } & 137 & 80.1\end{array}$

$\begin{array}{lll}\text { Persistent severe cough } & 136 & 79.5\end{array}$

$\begin{array}{lll}\text { Inability to talk or walk } & 128 & 74.9\end{array}$

Inability to play $\quad 84 \quad 49.1$

Blue lips and nails $\quad 83 \quad 48.5$

$\begin{array}{lll}\text { Persist for 1-3 hours after medication } & 72 & 42.1\end{array}$

were significantly more likely to have poor knowledge of asthma than the mothers of male children (adjusted $\mathrm{OR}=3.68$; 95\% CI: 1.29-10.5) (Table 3).

The following risk factors for poor knowledge among mothers were also identified; illiteracy of mothers and young age ( $<30$ years). Similarly, the following risk factors for poor behaviours among mothers were identified: female sex of the child, illiteracy of mothers, young age $(<30$ years) and poor knowledge of asthma.

\section{Discussion}

Providing information and educating patients, families and communities about asthma self-management and cooperative care skills may help 


\begin{tabular}{lcc}
\hline $\begin{array}{l}\text { Table } 2 \text { Behaviours concerning bronchial asthma among mothers of asthmatic } \\
\text { children in Aseer, south-west Saudi Arabia }\end{array}$ & No. of mothers & \% ( $\boldsymbol{n}=\mathbf{1 7 1})$ \\
\hline Behaviour item & 171 & 100.0 \\
During asthma attacks & 153 & 89.5 \\
$\quad$ Give necessary medications & 141 & 82.5 \\
Massage child's chest or back & 125 & 73.1 \\
Let child cough to clear lung from mucus & 112 & 65.5 \\
Let child rest and minimize movements & 59 & 34.5 \\
Wait and see progress of wheeze & 50 & 29.2 \\
Give homemade herbal fluids & 36 & 21.1 \\
Ask for help & 16 & 9.4 \\
Give water or juices & & \\
Give child breathing exercises & 171 & 100.0 \\
Prevention of asthma attacks & 161 & 94.2 \\
Regular intake of medications & 158 & 92.4 \\
Clean house to remove dust & 132 & 77.2 \\
Remove aggravating factors from house & 116 & 67.8 \\
Treat common cold attacks & 112 & 65.5 \\
Let child cough to get rid of mucus & 75 & 43.9 \\
Let child relax & 57 & 33.3 \\
Prevent severe exhaustion & 24 & 14.1 \\
Prevent severe exercise & & \\
Regular practice of breathing exercises & & \\
\hline
\end{tabular}

reverse the increase in asthma morbidity and mortality rates [9]. Good general knowledge of both patients and parents about asthma and medications is associated with better compliance and asthma management, leading to better control of asthma [10].

The results of the present study in Aseer region highlight some deficiencies in mothers' knowledge about asthma. This might be explained by the lack of availability of structured health education programmes designed for asthmatic patients and their families. Physicians generally do not give a high priority in their practice to the tasks of patient education, development of self-management skills and assumption of an appropriate degree of responsibility for paediatric asthma care because these require a substantial commitment of time and effort [11].
Regarding mothers' actions for managing their child's asthma, the great majority responded by giving medications and going to the physician. The great majority of mothers said they sought help from the doctor or other social support during their child's asthma attacks. This can be due to the chronic and unpredictable nature of asthma attacks. The action least mentioned by mothers for managing asthmatic attacks was breathing exercises. This points to mothers' ignorance of the importance of breathing exercises, presumably because local doctors had not educated them about such exercises and how to perform them, or to an inability of the children to practise them. These exercises, if practised regularly, help to strengthen the respiratory muscles and reverse the conditions which aggravate asthma attacks [12].
Our study identified the following risk factors for poor knowledge and behaviours among mothers: mother's illiteracy and young age and child's female sex. Older mothers had more knowledge than younger mothers. This might be because they get more experience and cognition through social learning in order to understand the disease better and to seek information about it.

The sex of the child is one of the documented determinants of health care utilization for respiratory symptoms in developed countries too $[13,14]$. Gender roles affect the entire process of health care seeking, not only illness-reporting but also the decision to choose a health care provider and how much to spend on the sick child [15].

The present study showed that there was a significant relationship between mothers' knowledge of asthma and their asthma management behaviour. The reasons for parental noncompliance with asthma care are complex and involve psychological, social and cultural factors. An important contributory factor, however, may be inadequate parental knowledge of asthma management techniques [16].

As our knowledge about the risk factors and means of preventing asthma increases, there is likely to be a greater focus on the behaviour and practices of family carers. These will require the development of educational and behavioural interventions to translate new knowledge regarding primary prevention into actual reductions in asthma prevalence $[17,18]$.

More education is needed in this region to help the mothers of asthmatic children acquire the necessary knowledge and practices to care for their children. 


\begin{tabular}{|c|c|c|c|c|c|c|}
\hline \multirow[t]{2}{*}{ Risk factor } & \multicolumn{3}{|c|}{ Poor knowledge $^{a}$} & \multicolumn{3}{|c|}{ Poor behaviours $^{\mathrm{a}}$} \\
\hline & No. & $\%^{\mathrm{a}}$ & aOR $(95 \% \mathrm{Cl})$ & No. & $\%^{\mathrm{a}}$ & aOR $(95 \% \mathrm{CI})$ \\
\hline \multicolumn{7}{|l|}{ Child's age } \\
\hline Preschool & 54 & 79.4 & $2.10(0.73-6.05)$ & 40 & 58.8 & $2.47(0.80-7.59)$ \\
\hline School age & 49 & 47.6 & & 25 & 24.3 & \\
\hline \multicolumn{7}{|l|}{ Child's sex } \\
\hline Female & 83 & 73.5 & $3.68(1.29-10.5)$ & 59 & 52.2 & $25.0(6.76-90.9)$ \\
\hline Male & 20 & 34.5 & & 06 & 10.3 & \\
\hline \multicolumn{7}{|c|}{ Duration of asthma (years) } \\
\hline$<2$ & 38 & 73.1 & $2.80(0.98-7.98)$ & 19 & 36.5 & $0.98(0.30-3.17)$ \\
\hline $2+$ & 65 & 54.6 & & 46 & 38.6 & \\
\hline \multicolumn{7}{|c|}{ Mother's age (years) } \\
\hline$<30$ & 69 & 82.1 & $6.18(2.15-17.7)$ & 56 & 66.7 & $5.78(1.74-19.2)$ \\
\hline $30+$ & 34 & 39.1 & & 09 & 10.3 & \\
\hline \multicolumn{7}{|c|}{ Mother's education } \\
\hline Illiterate & 29 & 98.7 & $62.3(13.5-288.0)$ & 28 & 93.3 & $20.8(2.92-142.8)$ \\
\hline Educated & 74 & 52.4 & & 37 & 26.2 & \\
\hline \multicolumn{7}{|c|}{ Mother's occupation } \\
\hline Not working & 71 & 58.2 & $0.58(0.20-1.70)$ & 49 & 40.1 & $1.09(0.57-6.8)$ \\
\hline Working & 32 & 65.3 & & 16 & 38.8 & \\
\hline \multicolumn{7}{|c|}{ Father's education } \\
\hline Illiterate & 16 & 84.2 & $2.21(0.34-14.4)$ & 10 & 52.6 & $1.09(0.65-2.31)$ \\
\hline Educated & 87 & 57.2 & & 55 & 36.1 & \\
\hline \multicolumn{7}{|c|}{ Mother's knowledge of asthma } \\
\hline Poor & - & - & - & 55 & 53.4 & $5.12(1.35-9.78)$ \\
\hline Good & - & - & - & 10 & 14.7 & \\
\hline
\end{tabular}

aLess than the 50th percentile.

$a O R=$ adjusted odds ratio; $C l=$ confidence intervals

\section{References}

1. Masoli $\mathrm{M}$ et al. The global burden of asthma: executive summary of the GINA Dissemination Committee Report. Allergy, 2004, 59:469-478.

2. Al Frayh AR et al. Increased prevalence of asthma in Saudi Arabia. Annals of allergy, asthma and immunology, 2001, 86(3):292-296.

3. Al Frayh A, Al Jawadi TQ. Prevalence of asthma among Saudi school children. Saudi Medical Journal, 1992, 13:521-524.

4. Alshehri MA et al. Screening for asthma and associated risk factors among urban school boys in Abha city. Saudi Medical Journal, 2000, 21(11):1048-1053.

5. Al-Ghamdi BR et al. Altitude and bronchial asthma in southwestern Saudi Arabia. Eastern Mediterranean Health Journal, 2007, 13(6):900-905.

6. Lwanga SK, Lemeshow S, eds. Sample size determination in health studies. Geneva, World Health Organization, 1990.

7. Grant EN et al. Development of a survey of asthma knowledge, attitudes, and perceptions: the Chicago Community Asthma Survey. Chicago Asthma Surveillance Initiative Project Team. Chest, 1999, 116(4 Suppl. 1):178S-183S.
8. Khalil E et al. Health behaviours of asthmatic children and their parents in Alexandria. Bulletin of the High Institute of Public Health, 1999, 26(4):115-121.

9. McQuaid E et al. Medication adherence in pediatric asthma: reasoning, responsibility, and behaviour. Journal of Pediatric Psychology, 2003, 28(5):323-333.

10. Flores $\mathrm{G}$ et al. Keeping children with asthma out of hospitals: parents' and physicians' perspectives on how pediatric asthma hospitalizations can be prevented. Pediatrics, 2005, 116:957-965.

11. Cohen S, Wamboldt F. The parent-physician relationship in pediatric asthma care. Journal of Pediatric Psychology, 2000, 25(5):69-77.

12. Hassed C. An integrative approach to asthma. Australian Family Physician, 2005, 34(7):513-608.

13. WHISTLER Study Group. Determinants of health care utilization for respiratory symptoms in the first year of life. Medical care, 2007, 45(8):746-752.

14. Pandey A et al. Gender differences in healthcare-seeking during common illnesses in a rural community of West Ben- 
gal, India. Journal of Health, Population, and Nutrition, 2002, 20(4):306-311.

15. Pokhrel $\mathrm{S}$ et al. Gender role and child health care utilization in Nepal. Health policy, 2005, 74:100-109.

16. Conway $\mathrm{C}$ et al. A pilot study describing local residents' perceptions of asthma and knowledge of asthma care in selected Chicago communities. Chest, 1999, 116:229-234.
17. Aziz NA et al. Skills amongst parents of children with asthma: a pilot interventional study in primary care setting. Medical Journal of Malaysia, 2006, 61(5):534-539.

18. Peterson-Sweeney K et al. Impact of asthma education received from health care providers on parental illness representation in childhood asthma. Research in Nursing and Health, 2007, 30(2):203-212.

\section{Facts about asthma}

- WHO estimates that 300 million people currently suffer from asthma. Asthma is the most common chronic disease among children.

- Asthma is a public health problem not just for high-income countries; it occurs in all countries regardless of the level of development. Most asthma-related deaths occur in low- and lower-middle income countries.

- Asthma is under-diagnosed and under-treated. It creates substantial burden to individuals and families and often restricts individuals' activities for a lifetime.

Source: WHO Fact sheet, No. 307

May 2008 